\title{
Corporate Greed and its Effect on Customer Satisfaction, Corporate Social Responsibility and Corporate Reputation among Customers: An Abstract
}

\author{
Albert Caruana, Joseph Vella, Jirka Konietzny, and Saviour Chircop
}

\begin{abstract}
Corporate greed has received increasing attention in recent years with various stories hitting the headlines. Customer satisfaction and corporate social responsibility are known to have a positive effect on corporate reputation among customers, but perceived corporate greed is likely to impede their effect. Corporate greed, customer satisfaction, corporate social responsibility and corporate reputation are considered, and a research model is proposed. Data are collected from among commercial banking customers, and mediated regression analyses are undertaken. The effect of corporate greed on corporate social responsibility is found to be stronger than on customer satisfaction, while the effect of corporate greed on corporate reputation is completely mediated via customer satisfaction and corporate social responsibility. Implications are discussed, limitations are noted and possible areas for further research are indicated.
\end{abstract}

References Available Upon Request

\footnotetext{
A. Caruana $(\bowtie) \cdot J$. Vella $\cdot$ S. Chircop

University of Malta, Msida, Malta

e-mail: albert.caruana@um.edu.mt; joseph.m.vella@um.edu.mt; savior.chircop@um.edu.mt

J. Konietzny

Luleå University of Technology, Luleå, Sweden

e-mail: jirka.konietzny@1tu.se
} 